\title{
Acquired Trisomy 21 - A Unique Cytogenetic Finding in T-Cell Acute Lymphoblastic Leukemia
}

\author{
Qurratulain Rizvi ${ }^{1}$, Aisha Jamal ${ }^{1}$, Jawad Hassan ${ }^{2}$ and Tahir Shamsi ${ }^{1, *}$ \\ ${ }^{1}$ Department of Clinical Haematology National Institute of Blood Diseases and Bone Marrow Transplantation, Karachi, Pakistan. \\ ${ }^{2}$ Department of Molecular Cytogenetics, National Institute of Blood Diseases and Bone Marrow Transplantation, Karachi, Pakistan.
}

\begin{abstract}
Acute lymphoblastic leukemia (ALL), is a lymphoid neoplasm arising from lymphoid progenitors, broadly classified according to lineage into B-cell and T-cell ALL in which T-cell ALL constitutes a small proportion. We are reporting here a case of young female who was diagnosed as T-cell ALL using flow cytometry with acquired trisomy 21, identified on conventional cytogenetics, as a unique finding in this case.
\end{abstract}

Keywords: Acute lymphoblastic leukemia, Acquired trisomy 21, Cytogenetics, Karyotyping, Lymphadenopathy, T-cell ALL. doi.org/10.21089/njhs.23.0135

\section{INTRODUCTION}

Acute lymphoblastic leukemia (ALL) is a lymphoid neoplasm arising from lymphoid progenitors undergone sustained genetic insults and thereby leading to malignant transformation. It constitutes a major bulk of pediatric acute leukemia and accounts for about $20 \%$ cases of adult ALL. It comprises of two varieties, either derived from B lymphocytes which is known as B-Cell ALL or from T-lymphocytes known to be T-cell ALL. The incidence of T-cell ALL is around $20 \%$ and found to be occurring in mostly adult population. In general, the treatment outcome is favorable in Bcell ALL as compared to T-cell ALL. The role of cytogenetics is not well defined in T-cell ALL [1]. We are reporting here an unusual cytogenetic finding of acquired trisomy 21 found at baseline in a patient with T-cell ALL. Trisomy 21 is considered to be acquired when the phenotypic features pertinent to down syndrome are absent. There is proven enhanced leukemogenic potential in constitutional down syndrome [2]. The role of acquired trisomy 21 is relatively well documented in cases of B-cell ALL, but there is no such defined role in T-cell ALL.

\section{CASE}

A 22-year old girl with no known co-morbid was presented with complain of low grade fever for two months. There was no significant personal, past medical or family history. On examination, she was vitally stable with unremarkable sys temic examinations. There was no lymphadenopathy or

*Address correspondence to this author at the National Institute of Blood Diseases and Bone Marrow Transplantation, ST 2/A, Block-17 Gulshan-eIqbal, Karachi, Pakistan. E-mail: t.shamsi.62@gmail.com hepatos-plenomegaly. Her complete blood counts revealed $\mathrm{Hb} 6.4 \mathrm{~g} / \mathrm{dl}$, white cell count of $43.36 \times 10^{9} / \mathrm{L}$ (absolute neutrophil count $0.47 \times 10^{9} / \mathrm{L}$ and absolute lymphocyte count of $32.3 \times 10^{9} / \mathrm{L}$ ) with platelet count of $98 \times 10^{9} / \mathrm{L}$. Microscopic examination of peripheral smear showed medium to small size blast cells with scant agranular cytoplasm, having high nuclear/cytoplasmic ratio (Fig. 1).

Flowcytometry on peripheral blood demonstrated high expression of CD3, CD5, CD7, CD45, CD33 and CD34. TdT, cMPO, CD79a, CD13, CD117, CD20, CD10, and CD19 were negative, culminating the inference of T-cell ALL . The absence of Tdt is an exceptional finding but rare cases of TdT negative T-cell ALL have been reported in literature. Its absence confers a poor prognosis [3]. The expression of myeloid lineage in ALL has also been reported in $10-15 \%$ of cases. Pan myeloid antigen expression in lymphoid leukemia may suggest presence of Philadelphia chromosome. The cytogenetics analysis revealed a normal female karyotype with an additional chromosome $21(47, \mathrm{XX},+21)$ in 09 metaphases, while 06 metaphases did not reveal any abnormality (Figs. 2, 3). Unfortunately, after detailed family counselling about treatment options and prognosis of disease, the family declined any curative treatment and opted for supportive care.

\section{DISCUSSION}

T-cell ALL is malignant neoplasm, constituting a small bulk of overall ALL. It originates from lymphoid tissue and belongs to T-cell lineage. It is a disease with variable biological heterogeneity. Despite of having an overall poor prognosis, along with other risk factors associated with this neoplasm, an insight into the cytogenetics and molecular studies 
may provide a ray of hope towards better treatment options. T-cell ALL cytogenetics usually reveals structural chromosomal aberrations, as determined by conventional karyotyping in about $50 \%$ of cases. Numerical changes are rare except for tetraploidy which has an incidence of 5\% and imparts no clinical significance. Cytogenetics usually unravels normal karyotype. Cryptic abnormalities detected via fluorescence in situ hybridization (FISH) technique demonstrates deletions at $9 \mathrm{p} 21$ and at $1 \mathrm{p} 32$, translocation $\mathrm{t}(5 ; 14)$ and rearrangements of $\mathrm{T}$-cell receptor $\mathrm{B}(T C R B)$ at $7 \mathrm{q} 34$ and $9 \mathrm{q} 34$ breakpoints [4].

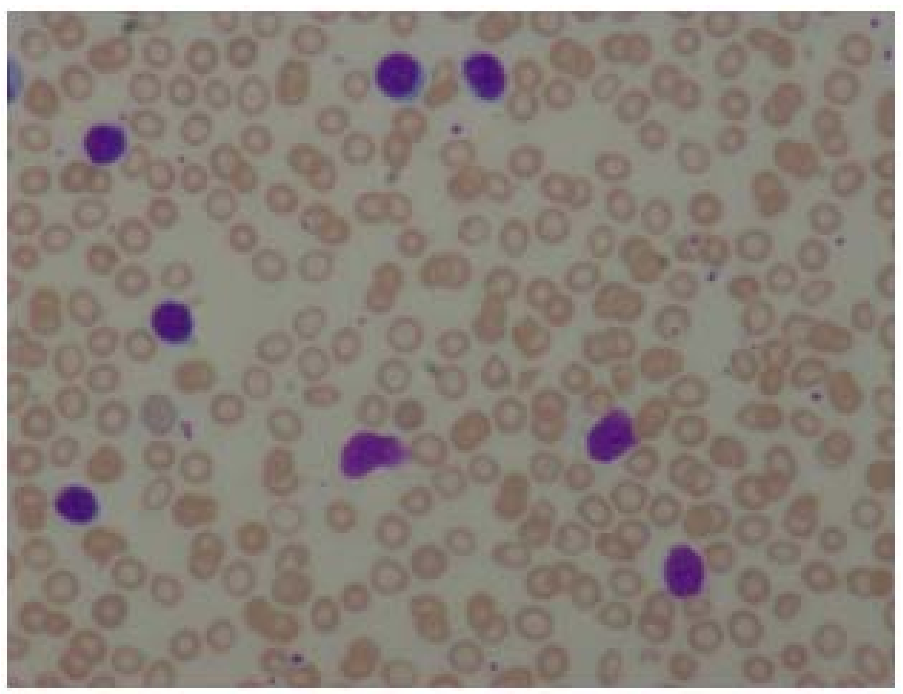

Fig. (1). Peripheral smear illustrating small sized blast cells having high nuclear to cytoplasmic ratio with scant, light basophilic agranular cytoplasm.

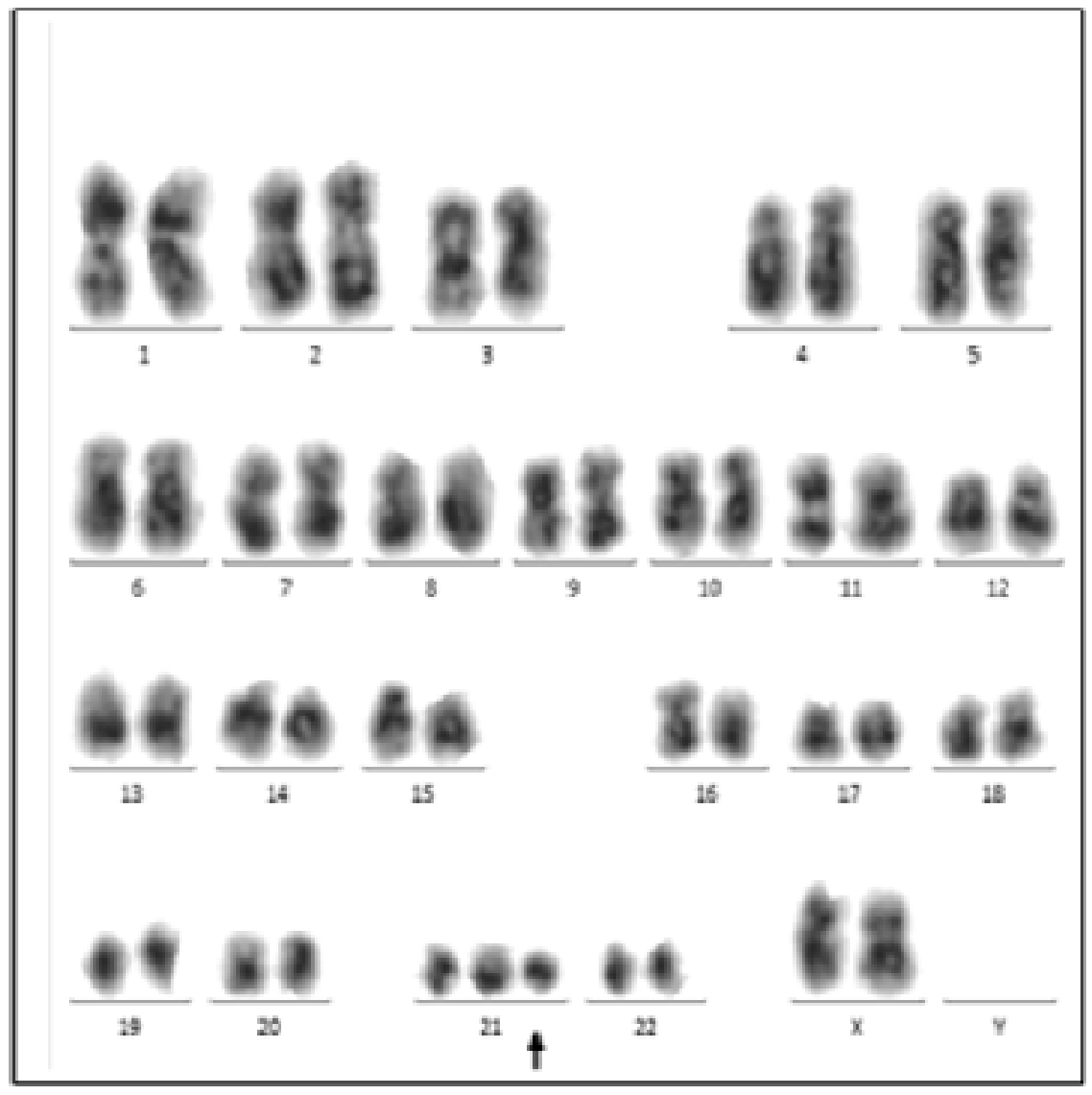

Fig. (2). Trisomy 21 identified in 9 out of 15 metaphases with 47 XX karyogram. 

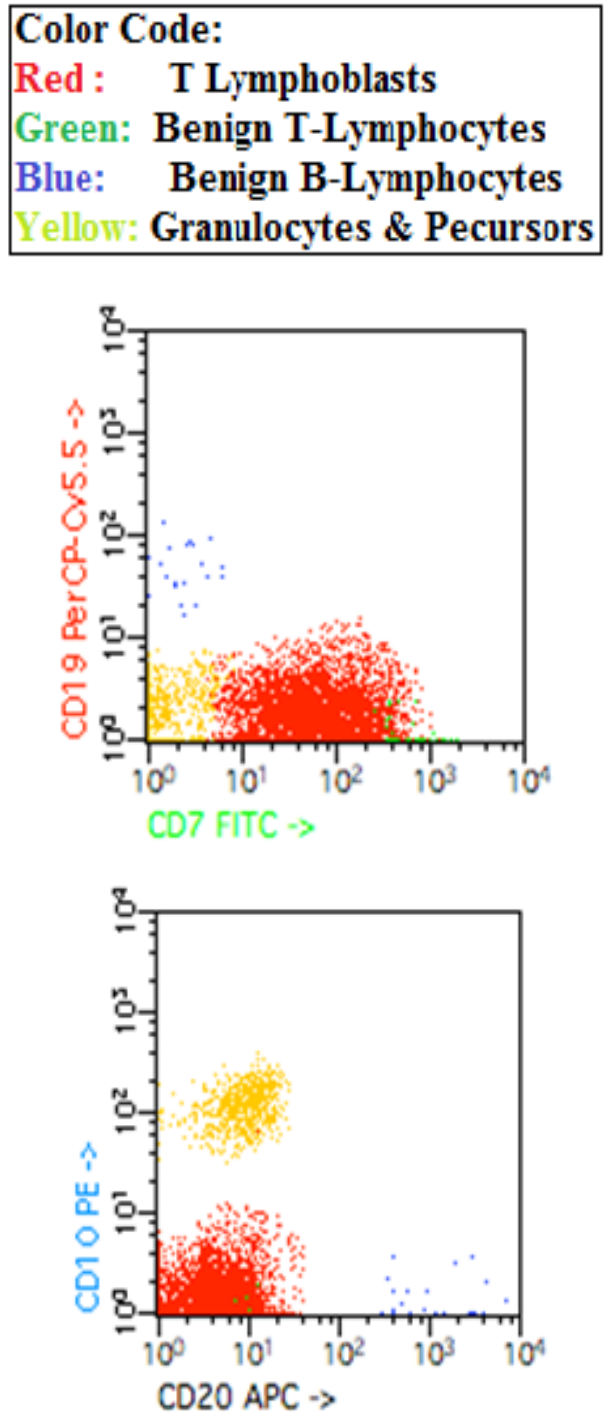

Fig. (3). Dot and plot representation of immunophenotypical markers.

According to the best of our knowledge, very scarce cases of acquired trisomy 21 have been reported in T-cell ALL in literature [5-7]. Acquired trisomy 21 is defined as gain of chromosome at locus 21 with lack of phenotypic features of typical Down's Syndrome. It differs from constitutional down syndrome (DS) which is a factor that predisposes to paediatric leukemias. Acquired trisomy 21 has association with certain haematological malignancies such as myelodysplatic syndrome, myeloproliferative neoplasm, acute myeloid leukemia, but has never been documented as a sole abnormality. It has been observed in B-cell ALL as sole clonal abnormality, accounting for about $2 \%$ cases of paediatrics and less than $1 \%$ cases of adult ALL cases (essentially
B lineage) [8]. There is prognostic ambiguity with regard to the prognostic significance of this acquired trisomy. In literature search, Cheng et al. [2] has clearly stated the poor prognosis imparted by the presence of trisomy 21 in ALL. Though this observation remains ambiguous as Atlas of genetics and cytogenetics in oncology and hematology reports trisomy 21 to confer a better overall survival when exist as a sole cytogenetic abnormality in childhood ALL; its role in adult ALL remains undetermined.

Prospective studies are needed to identify the role of numerical chromosomal abnormalities in T-cell ALL and therefore attempts can be made to tailor management approach.

\section{CONFLICT OF INTEREST}

Declared none.

\section{ACKNOWLEDGEMENT}

Declared none.

\section{REFERENCES}

[1] Litzow MR, Ferrando AA. How I treat T-cell acute lymphoblastic leukemia in adults. Blood, 2015; 126(7): 833-41. DOI: 10.1182/blood-2014-10-551895

[2] Cheng $\mathrm{Y}$, Wang $\mathrm{H}$, Wang $\mathrm{H}$, Chen Z, Jin J. Trisomy 21 in patients with acute leukemia. Am. J. Hematol., 2009; 84(3): 193-4. DOI: 10.1002/ajh.21339

[3] Zhou Y, Fan X, Routbort M, Yin CC, Singh R, Bueso-Ramos C, et al. Absence of terminal deoxynucleotidyl transferase expression identifies a subset of high-risk adult T-lymphoblastic leukemia/lymphoma. Mod. Pathol., 2013; 26(10): 1338-45.

[4] Graux C, Cools J, Michaux L, Vandenberghe P, Hagemeijer A. Cytogenetics and molecular genetics of T-cell acute lymphoblastic leukemia: from thymocyte to lymphoblast. Leukemia, 2006; 20(9): 1496-510. DOI: 1496-1510. 10.1038/sj.leu.2404302

[5] Watson MS, Carroll AJ, Shuster JJ, Steuber CP, Borowitz MJ, Behm FG, et al. Trisomy 21 in childhood acute lymphoblastic leukemia: a pediatric oncology group study (8602). Blood, 1993; 82(10): 3098-102.

[6] Dewald GW, Diez-Martin JL, Steffen SL, Jenkins RB, Stupca PJ, Burgert EO. Hematologic disorders in 13 patients with acquired trisomy 21 and 13 individuals with Down syndrome. Am. J. Med. Genet., 2005; 37(7): 247-50. DOI: 10.1002/ajmg.1320370750

[7] Raimondi SC, Pui CH, Head D, Behm F, Privitera E, Roberson PK, et al. Trisomy 21 as the sole acquired chromosomal abnormality in children with acute lymphoblastic leukemia. Leukemia, 1992; 6(3): 171-5.

[8] Viguié F. +21 or trisomy 21. France: Atlas Genet Cytogenet Oncol Haematol; 2001 [cited 2017 Jul 3]. Available from: atlasgeneticsoncology.org/Anomalies/tri21ID1041.html 